\title{
JUDICIALIZAÇÃO DA POLÍTICA NO ÂMBITO DO CONTROLE ORÇAMENTÁRIO E A CONTROLABILIDADE DE POLÍTICAS PÚBLICAS
}

\section{Carolina Leite Amaral Fontoura ${ }^{1}$}

\section{Resumo}

Está em curso um processo de crescente ampliação do poder jurisdicional sobre as políticas públicas e os gastos estatais, processo iniciado a partir da extensão das competências do Tribunal de Contas da União elencadas na Constituição Brasileira de 1988, que tem relação com a nova concepção de Estado Democrático de Direito que surgia. Tal fenômeno pode ser chamado de judicialização da política no âmbito do controle orçamentário, e guarda forte similitude com a já conhecida judicialização da política protagonizada por juízes que imbuídos de postura ativista passam a "criar" o direito, ocasionando uma verdadeira transferência do poder de legislar, antes exclusivo aos poderes legislativo e executivo, no caso, para os juízes e tribunais de contas. Tal agigantamento das funções no âmbito de Tribunais de Contas, instituições cujas atribuições estão delimitadas constitucionalmente, gera uma série de novos desafios. Por meio da análise das estratégias argumentativas e práticas institucionais expostas pelo Tribunal de Contas da União em decisões, à luz de suas competências legais e constitucionais, é possível debater os limites desse processo de "domesticalização" da política e os dilemas estruturais decorrentes do aumento de sua atuação no atual Estado Constitucional Brasileiro. É preciso avaliar os limites e a extensão do controle por ele exercido sobre as demais esferas estatais, principalmente o Executivo, grande executor de políticas públicas discricionárias, bem como aferir se em suas decisões emblemáticas leva em conta questões consequencialistas, pois é sabido que possuem potencial de provocar forte impacto no comportamento de outros atores políticos.

Palavras-Chave: Judicialização da política; análise de discurso; Tribunal de Contas da União; políticas públicas; discricionariedade administrativa; separação de poderes.

\section{INTRODUÇÃO}

O fenômeno da expansão do poder jurisdicional no âmbito do Estado Democrático de Direito foi intensamente debatido e rotulado por alguns autores de judicialização da política. ${ }^{2}$ Tal acontecimento é caracterizado por uma postura ativista "criativa" dos juízes, ocasionando assim uma espécie de transferência da

\footnotetext{
${ }^{1}$ Mestrado em Direito, Linha de Pesquisa Teorias da Decisão e Desenhos Institucionais. E-mail: carolina.fontoura@gmail.com

${ }^{2}$ WERNECK VIANNA, Luiz et al. A judicialização da política e das relações sociais no Brasil. Rio de Janeiro: Revan, 1999; CASTRO, Marcus Faro de. O Supremo Tribunal Federal e a Judicialização da Política. Revista Brasileira de Ciências Sociais, n. 34, vol. 12, jun 1997, p. 147-156 e SANTOS, Fabiano. O Poder Legislativo no Presidencialismo de Coalizão. Belo Horizonte: Ed, UFMG; Rio de Janeiro: IUPERJ, 2003.
} 
função legislativa, antes concentrada nos poderes Legislativo e Executivo, a atores que não foram eleitos para tanto, na qualidade de representantes do povo ${ }^{3}$.

Por outro lado, a influência do Poder Judiciário e de seu raciocínio se ampliou com esse processo, sendo visível a utilização no campo político, cada vez mais, de procedimentos judiciais por parte de agências executivas e legislativas. ${ }^{4}$

Poderíamos conceituar judicialização da política como a utilização de procedimentos judiciais para a resolução de conflitos de ordem política, tais como controvérsias a respeito de normas, resoluções e políticas públicas em geral, adotadas ou implementadas pelos Poderes Executivo e Legislativo. ${ }^{5}$ Ao participar do processo de políticas públicas, o Julgador pode intervir ou em alguns casos até alterar o status quo anterior, no entanto, interessante notar que enquanto o Judiciário age por provocação diante do princípio da inércia, o Tribunal de Contas da União (TCU) pode agir de ofício, o que per si evidencia o impacto da sua atuação.

Assim, é possível vermos o fenômeno da judicialização por um novo viés, que é o da apropriação de procedimentos judiciais por espaços ditos como não jurídicos, como os Tribunal de Contas, com recursos e julgamentos, a partir do exercício do poder de controle sobre os poderes políticos. Dessa forma, o Tribunal de Contas da União (TCU) emerge como forte ator político, incorporando uma real função de judicatura na esfera de controle externo face as políticas públicas e escolhas de alocação de recursos, evento que nos propomos a analisar.

Muito embora a instituição, no Brasil, do Tribunal de Contas enquanto corte fiscalizatória remonte ao início da República, foi com a Constituição Federal de 1988 que passou a deter poderes fiscalizatórios mais efetivos. A nova definição de atribuições prevê uma extraordinária ampliação do poder de controle do Tribunal, já que passou a "julgar as contas dos administradores e demais responsáveis por dinheiros, bens e valores públicos da administração direta e indireta". ${ }^{6}$

Tal ampliação se deu no bojo de um processo democratizador que marcou a passagem de um modelo político autoritário para um modelo governamental constitucional de base democrática. O modelo ditatorial anterior influenciou também, como não poderia deixar de ser, o funcionamento da Corte de Contas, como no caso da suspensão das garantias constitucionais inerentes ao Poder Judiciário, também desfrutadas pelos juízes de

\footnotetext{
${ }^{3}$ Art. $1^{\circ}$, Parágrafo único. Todo o poder emana do povo, que o exerce por meio de representantes eleitos ou diretamente, nos termos desta Constituição.

${ }^{4}$ TATE, Neal. Why the expansion of judicial power? In: TATE, Neal; VALLINDER, Torbjörn. The Global Expansion of judicial power. New York: New York University Press, 1995.p. 27-37.

${ }^{5}$ DE OLIVEIRA, Vanessa Elias. Judiciário e Privatizações no Brasil: Existe uma Judicialização da Política? Dados - Revista de Ciências Sociais [On-line] vol. 48, núm. 3, julho-setembro, 2005, pp. 559-587, Universidade do Estado do Rio de Janeiro, Brasil. Disponível em:<http:/ / www.redalyc.org/articulo.oa?id=21848304>

${ }^{6}$ Art. 71, inciso II, CRFB/88.
} 
contas e da atividade legislativa diante dos diversos atos institucionais. Esse cenário enfraqueceu instituições responsáveis pelo controle externo, como o TCU, que tinham o funcionamento extremamente incipiente. ${ }^{7}$

No entanto, após o incremento constitucional de suas funções, o Tribunal não vem se mostrando apto a funcionar conforme as regras democráticas e dentro de suas atribuições de fiscalização financeira. Uma das razões dessa inadequação é seu posicionamento como instrumento de controle e correção dos atos executivos; função essa que muitas vezes implica na interferência em processos políticos de definição de políticas públicas, bem como, no próprio comportamento dos atores políticos.

A interferência direta e indireta da Corte de Contas no âmbito de atuação dos gestores públicos dotados de representação popular chamada judicialização da política é um fenômeno contemporâneo intenso ${ }^{8}$, mostrando-se imprescindível seu estudo e análise, de forma que essa instituição seja capaz de exercer seu devido papel no regime democrático atual, evitando que inadvertidamente use de sua autoridade, sensivelmente ampliada pela Constituição Federal de 1988, para ocupar o papel de representante da vontade popular, que constitucionalmente não lhe cabe, e com isso atrapalhe processos de efetivação de políticas públicas estatais discricionárias, desrespeitando o princípio democrático.

Essa adoção de mecanismos judiciais em arenas de deliberação política, o fato de juízes de contas passarem a interferir em políticas governamentais é de fato parte da ideia de judicialização da política. Nesse sentido:

Sob condições que sejam favoráveis, a judicialização [da política] se desenvolve apenas porque os juízes decidem que devem (1) participar da tomada de decisão política que poderia, de outra forma, ser deixada à discrição, criteriosa ou arbitrária, de outras instituições e, ao menos ocasionalmente, (2) substituir as decisões políticas emanadas de outras instituições por aquelas emanadas deles mesmos. ${ }^{9}$

Em face desse cenário, surgem diversos questionamentos, para os quais ainda não há respostas satisfatórias: qual deve ser o papel a ser desempenhado pelo TCU em uma sociedade democrática? Em que medida as decisões do Tribunal interferem na tomada de decisões políticas? Até que ponto pode ser considerado um órgão auxiliar do Poder Legislativo no controle externo, e não um órgão autônomo que atua em regime de cooperação com àquele? Como deve se dar a fiscalização em face das políticas públicas, considerando a reserva da administração em efetivar escolhas discricionárias?

\footnotetext{
${ }^{7}$ PESSANHA, Charles. O congresso externo sob o controle das contas do tribunal de contas. Revista Insight Inteligência, n 21 , p.124. Disponível em: <http://www.insightinteligencia.com.br/21/>.

${ }^{8}$ (...) Cortes tornaram-se cada vez mais lugares onde política substancial é feita. Em terceiro lugar, os juízes têm ficado cada vez mais dispostos a regular a conduta da atividade política em si — se praticado em ou ao redor de legislaturas, agências ou o eleitorado construindo e fazendo cumprir padrões de comportamento aceitáveis para grupos de interesse, partidos políticos e pessoas públicas nomeadas e eleitas. FEREJOHN, John. Judicializing Politics, Politicizing Law. p.42. Disponível em< http://www.law.duke.edu/journals/65LCPFerejohn.>. (tradução nossa)

${ }^{9}$ DE OLIVEIRA, op.cit; p.3.
} 


\section{O TRIBUNAL DE CONTAS E SUA FUNÇÃO FISCALIZATÓRIA NA DEMOCRACIA BRASILEIRA}

\section{Mapeamento normativo e institucional acerca do funcionamento da corte de contas e seu caráter político}

O controle da Administração Pública Brasileira divide-se em interno, realizado no âmbito de cada poder, auxiliando o controle externo na apuração de eventuais falhas, nos moldes do Art. $74 \mathrm{da} C R F B / 88^{10}$, e externo, que ficou a cargo do Congresso Nacional "exercido com o auxílio do Tribunal de Contas da União", conforme prescreve o Art. 71 da CRFB/88. ${ }^{11}$

Os sistemas de controle externo podem se dividir em sistemas de Cortes de Contas ou Tribunais de Contas ou de Auditorias Gerais ou Controladorias. Os primeiros privilegiam o controle de legalidade face aos atos administrativos fiscalizados, enquanto o segundo preconiza a questão do desempenho de seus fiscalizados enquanto instituições. No Brasil prevalece o primeiro, embora não se restrinja apenas a aferição da legalidade, pois a Constituição inseriu à época da ampliação, a competência para avaliar à economicidade e legitimidade dos gastos públicos ${ }^{12}$, muito embora não tenha delineado como tal controle seria exercido pela própria utilização de termos vagos e seu caráter analítico.

No Art. 49, inciso X, da CRFB $/ 88,{ }^{13}$ consta que o Congresso Nacional possuiria competência exclusiva para fiscalizar os atos do Poder Executivo, no entanto, mais à frente o Art. 71 preconiza que o TCU irá auxiliá-lo no exercício dessa função fiscalizadora, o que gera uma discussão se seria um mero órgão auxiliar ou autônomo. A doutrina diverge sobre o assunto, mas vem prevalecendo a ideia de autonomia desta Corte. ${ }^{14}$

\footnotetext{
${ }^{10}$ Art. 74. Os Poderes Legislativo, Executivo e Judiciário manterão, de forma integrada, sistema de controle interno com a finalidade de: I - avaliar o cumprimento das metas previstas no plano plurianual, a execução dos programas de governo e dos orçamentos da União; II - comprovar a legalidade e avaliar os resultados, quanto à eficácia e eficiência, da gestão orçamentária, financeira e patrimonial nos órgãos e entidades da administração federal, bem como da aplicação de recursos públicos por entidades de direito privado; III - exercer o controle das operações de crédito, avais e garantias, bem como dos direitos e haveres da União; IV - apoiar o controle externo no exercício de sua missão institucional. $\$ 1^{\circ}$ - Os responsáveis pelo controle interno, ao tomarem conhecimento de qualquer irregularidade ou ilegalidade, dela darão ciência ao Tribunal de Contas da União, sob pena de responsabilidade solidária. $\$ 2^{\circ}$ - Qualquer cidadão, partido político, associação ou sindicato é parte legítima para, na forma da lei, denunciar irregularidades ou ilegalidades perante o Tribunal de Contas da União.

${ }^{11}$ Art. 71 . O controle externo, a cargo do Congresso Nacional, será exercido com o auxílio do Tribunal de Contas da União, ao qual compete (...)

${ }^{12}$ Art. 70. A fiscalização contábil, financeira, orçamentária, operacional e patrimonial da União e das entidades da administração direta e indireta, quanto à legalidade, legitimidade, economicidade, aplicação das subvenções e renúncia de receitas, será exercida pelo Congresso Nacional, mediante controle externo, e pelo sistema de controle interno de cada Poder. (grifos nossos)

${ }^{13}$ Art. 49. É da competência exclusiva do Congresso Nacional: X - fiscalizar e controlar, diretamente, ou por qualquer de suas Casas, os atos do Poder Executivo, incluídos os da administração indireta;

14 “2.1. Feita a ressalva, começo por dizer que o Tribunal de Contas da União não é órgão do Congresso Nacional, não é órgão do Poder Legislativo. Quem assim me autoriza a falar é a Constituição Federal, com todas as letras do seu art. 44, litteris: "O Poder Legislativo é exercido pelo Congresso Nacional, que se compõe da Câmara dos Deputados e do Senado Federal” (negrito à parte). Logo, o Parlamento brasileiro não se compõe do Tribunal de Contas da União. Da sua estrutura orgânica ou formal deixa de fazer vol.08, nº. 03, Rio de Janeiro, 2015. pp. 1421-1440 1424
} 
A própria análise do Art. 44 da CRFB $/ 88^{15}$ que trata da composição do Legislativo, não inclui o TCU enquanto órgão do mesmo, mencionando apenas o Senado e a Câmara dos Deputados. Trata-se de órgão independente, tendo em vista que suas atribuições vêm definidas pela própria Constituição, fato típico de órgãos independentes, como o Ministério Público, por exemplo.

O TCU se aproxima mais do Poder Judiciário do que se imagina, o próprio texto constitucional em seu Art.73 faz referência organizativa-operacional ao Poder Judiciário, afirmando que a Corte de Contas desempenhará sua "jurisdição em todo o território nacional, exercendo, no que couber, as atribuições previstas no art.96", artigo esse que trata das competências dos tribunais no âmbito do Judiciário. Acerca da expressão "no que couber", preconiza a doutrina que teríamos uma disposição mutatis mutandis, ou seja, faz-se a aplicação analógica mudando o que deve ser mudado diante das peculiaridades de uma Corte de Contas. ${ }^{16}$

A similitude não se restringe às atribuições, pois além dessas, os ministros julgadores das contas possuem status de magistrados, tendo como referencial os Ministros do Superior Tribunal de Justiça, nos moldes do Art. $73, \$ 3^{\circ}$ da $\mathrm{CRFB} / 88^{17}$. Dito isso, sabe-se que tais ministros possuem vitaliciedade em seus cargos, como os membros da magistratura, assim como os conselheiros dos Tribunais de Contas estaduais e municipais, criados antes da Constituição, já que a mesma não permite atualmente a criação de Cortes de Contas Municipais (Art.31, $\left.\$ 4^{\circ} \mathrm{da} \mathrm{CRFB} / 88\right)$.

No entanto, o TCU não é órgão integrante do Poder Judiciário, assim como não o é do Poder Legislativo, é órgão da pessoa jurídica União, diretamente, pairando em paralelo aos Três Poderes Federais, não pertencendo a nenhum deles. Dessa forma foi pensado desde suas primeiras concepções ${ }^{18}$, como Tribunal sui generis, autônomo em seu exercício fiscalizatório, o que impõe a reavaliação da afirmação equivocada de que seria mero órgão auxiliar. O texto constitucional apenas afirma que este Tribunal irá auxiliar o Poder Legislativo na função fiscalizatória acometida a ambos, embora esse seja o Poder responsável por tal função, e nem poderia ser diferente, já que a Constituição não erigiu as Cortes de Contas ao status de Poder.

parte a Corte Federal de Contas e o mesmo é de se dizer para a dualidade Poder Legislativo/Tribunal de Contas, no âmbito das demais pessoas estatais de base territorial e natureza federada." (BRITTO, Carlos Ayres. O Regime Constitucional dos Tribunais de Contas. Revista Diálogo Jurídico, Salvador, CAJ - Centro de Atualização Jurídica, v. I, no. 9, dezembro, 2001. Disponível em: <http://www.direitopublico.com.br>)

${ }^{15}$ Art. 44. O Poder Legislativo é exercido pelo Congresso Nacional, que se compõe da Câmara dos Deputados e do Senado Federal.

16 "Devendo-se entender o fraseado "no que couber" como equivalente semântico da locução mutatis mutandis; ou seja, respeitadas as peculiaridades de organização e funcionamento das duas categorias de instituições públicas (a categoria do Tribunal de Contas da União e a categoria dos órgãos que a Lei Maior da República eleva à dignidade de um tribunal judiciário).” Ibid; p.2.

${ }^{17} \$ 3^{\circ}$ - Os Ministros do Tribunal de Contas da União terão as mesmas garantias, prerrogativas, impedimentos, vencimentos e vantagens dos Ministros do Superior Tribunal de Justiça, aplicando-se-lhes, quanto à aposentadoria e pensão, as normas constantes do art. 40.

18 "Rui Barbosa também se manifesta no mesmo sentido: "Tribunal é, mas Tribunal sui generis. E explica: "corpo de magistratura intermediária à administração e à legislatura, que colocado em posição autônoma com atribuições de revisão e julgamento, cercado de garantias contra quaisquer ameaças, exerce funções vitais no organismo constitucional” (grifos nossos) (FERNANDES, Jorge Ulisses Jacoby. Tribunais de Contas do Brasil: jurisdição e competência. Belo Horizonte: Ed.Fórum, 2003.p.133) 
O que temos é um órgão público de controle externo, investido de poder jurisdicional em certas matérias, como a atribuição expressa de julgar as Contas de quem "utilize, arrecade, guarde, gerencie ou administre dinheiros, bem e valores públicos (Art. 70, \$ único e Art.71, inciso II da CRFB/88). Seria o exercício, a apropriação da função jurisdicional por um órgão de contas, em que pese haja doutrina em sentido contrário postulando que a jurisdição é monopólio do Judiciário, a exegese do texto constitucional não permite outra conclusão. Ademais, o Art. 73 atesta que "O Tribunal de Contas da União, (...) tem sede no Distrito Federal, (...) e jurisdição em todo o território nacional (...)”.

Em virtude do seu poder esclarecedor acerca da questão, trazemos as lições de Frederico Pardini sobre a controvérsia, no mesmo sentido da viabilidade do exercício da função jurisdicional pela Corte de Contas aqui defendida, a saber:

É claro que o conteúdo da jurisdição dos Tribunais do Poder Judiciário difere do conteúdo da jurisdição do Tribunal de Contas da União. O conteúdo da jurisdição do Tribunal de Contas, exercida com exclusividade, examina a legalidade, legitimidade e economicidade expressas pelos elementos e valores contidos na prestação ou na tomada de contas públicas; enquanto a jurisdição dos órgãos judicantes do Poder Judiciário, exercida, também, com exclusividade, examina a legalidade e, de certa forma, a moralidade, relativas ao comportamento, direito e deveres das duas partes que compõe a relação processual ${ }^{19}$

Demonstrada a premissa de que a Corte, ao exercer a função judicante das contas públicas, protagoniza a apropriação de procedimentos judiciais num espaço não-jurídico, começamos a delinear o fenômeno da judicialização da política no controle externo. Uma faceta essencial dessa análise reside na própria natureza da Corte de Contas e na sua caracterização enquanto Tribunal Administrativo e também Político, tema que passamos a abordar.

As atribuições do TCU são descritas no Art. 71 e seus onze incisos ${ }^{20}$, sua Lei Orgânica de n ${ }^{\circ}$ 8.443/199221 e Regimento Interno aprovado por meio da Resolução TCU no 246, de 30 de Novembro de $2011^{22}$. Isso implica dizer que o Poder Constituinte Originário optou por elencar as atribuições desse órgão de

\footnotetext{
${ }^{19}$ PARDINI, Frederico. Tribunais de contas: órgão de destaque constitucional. 1997. Tese (Doutoramento em direito público) Faculdade de Direito da Universidade Federal de Minas Gerais, Belo Horizonte.

${ }^{20}$ Art. 71 . O controle externo, a cargo do Congresso Nacional, será exercido com o auxílio do Tribunal de Contas da União, ao qual compete: (...) II - julgar as contas dos administradores e demais responsáveis por dinheiros, bens e valores públicos da administração direta e indireta, incluídas as fundações e sociedades instituídas e mantidas pelo Poder Público federal, e as contas daqueles que derem causa a perda, extravio ou outra irregularidade de que resulte prejuízo ao erário público;

${ }^{21}$ Art. $1^{\circ}$ Ao Tribunal de Contas da União, órgão de controle externo, compete, nos termos da Constituição Federal e na forma estabelecida nesta Lei: (...) I - julgar as contas dos administradores e demais responsáveis por dinheiros, bens e valores públicos das unidades dos poderes da União e das entidades da administração indireta, incluídas as fundações e sociedades instituídas e mantidas pelo poder público federal, e as contas daqueles que derem causa a perda, extravio ou outra irregularidade de que resulte dano ao Erário;

${ }^{22}$ Art. $1^{\circ}$ - Ao Tribunal de Contas da União, órgão de controle externo, compete, nos termos da Constituição Federal e na forma da legislação vigente, em especial da Lei no 8.443, de 16 de julho de 1992: I - julgar as contas de qualquer pessoa física ou jurídica, vol.08, n. 03, Rio de Janeiro, 2015.pp. 1421-1440 1426
} 
controle na fiscalização da Administração Pública Federal, ou seja, seu regime de atuação e dos agentes que o compõe é acima de tudo constitucional, razão pela qual não podemos pensá-lo como mero órgão administrativo. Quando o legislador quis, fez referência à legislação infraconstitucional no Art. 71, VIII da CRFB/ $88^{23}$ que trata das sanções passíveis de aplicação.

Surgido no cerne do processo de democratização que a nova Constituição instaurava, parte de um movimento político, evidencia-se o caráter também político dessa Corte. A Constituição pode ser entendida em seu sentido político, diferenciando-a da noção de lei constitucional, pois a primeira é produto de certa decisão política, seria a decisão política do titular do poder constituinte. Citando José Afonso da Silva sobre o sentido de Constituição, “....só se refere à decisão política fundamental (estrutura e órgãos do Estado, direitos individuais, vida democrática etc.); as leis constitucionais seriam os demais dispositivos inseridos no texto do documento constitucional, mas não contém matéria de decisão política fundamental”24

Dessa forma, o Governo e sua estrutura, seus órgãos de estatura política têm seu diploma jurídico próprio na Constituição e não na lei, embora a Administração enquanto executora de políticas públicas, por exemplo, aja de acordo com o princípio da legalidade (Art. 37, caput, da CRFB/88). A lei infraconstitucional dá continuidade à Lei Maior, que funciona como verdadeiro guia da primeira. Essas "linhas mestras dos órgãos públicos de existência necessária"25, tal qual o Tribunal de Contas, estão contidas no texto da Magna Carta. Não restam dúvidas acerca da caracterização do TCU enquanto tribunal político e administrativo, o que sedimenta o espaço de discussão acerca da avaliação sobre escolhas políticas dos gestores públicos.

Finalizando essa abordagem, trazemos a exposição valiosa do Ministro Aposentado do Superior Tribunal Federal (STF) Carlos Ayres Britto sobre a natureza política da Corte de Contas:

Daqui se infere que as Casas de Contas se constituem em tribunais de tomo
político e administrativo a um só tempo. Político, nos termos da
Constituição; administrativo, nos termos da lei. Tal como se dá com a
natureza jurídica de toda pessoa estatal federada, nesta precisa dicção
constitucional: "A organização político-administrativa da República
Federativa do Brasil compreende a União, os Estados, o Distrito Federal e os
Municípios, todos autônomos nos termos desta Constituição" (art. 18,
caput, negrito à parte). E salta à razão que se os Tribunais de Contas não
ostentassem dimensão política não ficariam habilitados a julgar as contas
dos administradores e fiscalizar as unidades administrativas de qualquer dos
três Poderes estatais, nos termos da regra insculpida no inciso IV do art. 71
da Carta de Outubro (salvante as contas anualmente prestadas pelo Chefe
do Poder Executivo). Sequer receberiam o nome de "Tribunais" e nunca

pública ou privada, que utilize, arrecade, guarde, gerencie ou administre dinheiros, bens e valores públicos ou pelos quais a União responda ou que, em nome desta, assuma obrigações de natureza pecuniária, bem como daqueles que derem causa a perda, extravio ou outra irregularidade de que resulte dano ao erário;

${ }^{23}$ Art. 71, VIII - aplicar aos responsáveis, em caso de ilegalidade de despesa ou irregularidade de contas, as sançôes previstas em lei, que estabelecerá, entre outras cominações, multa proporcional ao dano causado ao erário; (grifos nossos)

${ }^{24}$ Curso de direito constitucional positivo. 9. ed.rev. p.40. São Paulo: Malheiros, 1992.

${ }^{25}$ BRITTO, op.cit; p. 9 . 
teriam em órgãos e agentes judiciários de proa o seu referencial organizativooperacional. $^{26}$ (grifos nossos)

Ademais, há outro ponto a ser considerado, é o fator político existente no processo de indicação dos ministros que compõe o colegiado do Tribunal, nove no total. A primeira menção ao termo ministro foi feita na Constituição de 1934, sendo reproduzido pela atual, a qual impôs requisitos e critérios para a escolha desses ministros no Art. $73, \$ 1^{\circ}$, como idoneidade moral e reputação ilibada; idade acima de trinta e cinco anos e menos de sessenta e cinco anos de idade, etc, semelhantes aos impostos para os cargos providos por sistema de indicação, dentro do Poder Judiciário (Art. 101, caput, da CRFB/88).

Critérios relativos à idoneidade e reputação são deveras subjetivos e amplos, em que pese a possibilidade aberta com a decisão do STF em sede de Recurso Extraordinário na Ação Popular no 167.137-8-TO27, anulando a nomeação de dois conselheiros de Tribunal de Contas Estadual, atestando que os requisitos estatuídos nos dispositivos constitucionais tornam o ato administrativo de nomeação vinculado aos parâmetros objetivados pela CRBF/88, ainda há um longo caminho a percorrer.

Primeiro porque ao realizar uma busca pelas decisões referentes às impugnações, é perceptível que não são frequentes os casos de invalidação por desrespeito a esses requisitos "morais", a maioria dos casos analisados pela Corte Suprema se deve à violação na divisão proporcional das indicações entre os Poderes Legislativo e Executivo, quando parlamentares e governantes buscam manter sua prerrogativa de indicar ministros da Corte. ${ }^{28}$ Segundo porque o Judiciário não age de ofício, de forma que essa iniciativa depende de um controle social aprimorado por parte de instituições representativas, como entidades de classe, ministério público, etc, que possuam meios para impugnar as indicações e o façam efetivamente.

Sobre o processo de indicação há muitas críticas, seja pela ausência de concurso público para a nomeação ou pelo método de indicação, na proporção de um terço pelo Presidente da República, dois alternadamente dentre auditores e membros do Ministério Público junto ao Tribunal, todos com aprovação do Senado Federal, e dois terços inteiramente pelo Congresso Nacional, sem outras limitações além dos requisitos constitucionais (Art. $\left.73, \$ 2^{\circ} \mathrm{da} \mathrm{CRFB} / 88\right){ }^{29}$

\footnotetext{
${ }^{26}$ Ibid. p. 10.

${ }^{27}$ Brasil. Supremo Tribunal Federal, Recurso Extraordinário 167.137-8-TO, 2a Turma, Relator: Min. Paulo Brossard, Data de Julgamento: 18.10.1994, DJU 25.11.1994;

${ }^{28}$ TRIBUNAL DE CONTAS - COMPOSIÇÃO - "VAGA CATIVA" DA ASSEMBLEIA LEGISLATIVA - EGRESSO DO MINISTÉRIO PÚBLICO - ALCANCE DO ARTIGO 73, $\$ 2$, DA CONSTITUIÇÃO FEDERAL. Prevalece a regra constitucional de divisão proporcional das indicações entre os Poderes Legislativo e Executivo, revelado o critério da "vaga cativa", sobre a obrigatória indicação de clientelas específicas pelos governadores, inexistente exceção, incluída a ausência de membro do Ministério Público Especial. (Brasil. Supremo Tribunal Federal, Recurso Extraordinário 717424, Relator: Min. Marco Aurélio, Tribunal Pleno, Data de Julgamento: 21/08/2014, Repercussão Geral - Mérito Dje-213 Divulg. 29-10-2014 Public. 30-10-2014) ${ }^{29} \$ 2^{\circ}$ - Os Ministros do Tribunal de Contas da União serão escolhidos:

I - um terço pelo Presidente da República, com aprovação do Senado Federal, sendo dois alternadamente dentre auditores e membros do Ministério Público junto ao Tribunal, indicados em lista tríplice pelo Tribunal, segundo os critérios de antigüidade e merecimento;
} 
Diferentemente do Poder Judiciário que está adstrito aos limites legais para ditar o direito entre as partes, a Corte de Contas avalia se atos administrativos estão dentro das molduras da legalidade, legitimidade e economicidade, aproximando-se perigosamente dos limites meritórios do ato administrativo - impondo a avaliação da extensão de seu poder fiscalizatório face aos atos discricionários - podendo até sustar a execução de atos impugnados, em caso de desobediência a suas recomendações.

Na prática temos o fato questionável dos Poderes fiscalizados indicarem seus futuros fiscalizadores, talvez seja por isso que, em nosso país, jamais foram rejeitadas as contas prestadas por Presidentes da República, em parecer prévio do TCU ou em decisão final do Congresso Nacional..$^{30}$ Muito menos se vê notícias acerca de contas legislativas sendo julgadas com ressalvas, pois não se pode olvidar que o TCU também fiscaliza o Legislativo já que a Constituição não fez restrições, todo aquele que administra dinheiros, bens e valores públicos está constitucionalmente obrigado ao dever de prestar contas.

É preciso ressaltar que, no período democrático recente, o TCU, por diversas vezes, apontou ressalvas e recomendações nas contas presidenciais, embora tenham sido aprovadas posteriormente, o que já evidencia uma mudança de postura do órgão. No entanto, é no julgamento de atos e contratos administrativos governamentais que se vislumbra o crescimento exponencial do olhar duro revisional da Corte, pois sem deixar seu caráter político de lado, passa a posicionar-se como última palavra e ultrapassar os limites de suas competências fiscalizatórias.

Ao comentar o processo de nomeação de juízes federais no sistema norte- americano, Stephen M. Griffin assegura que mesmo se tornando menos "contencioso" e imprevisível no futuro, permanecerá politizado ${ }^{31}$. Acrescenta ainda, na mesma linda de outros autores ${ }^{32}$, que a politização depende do grau de importância que grupos políticos rivais atribuem ao controle dos tribunais, não sendo de hoje que os políticos têm visto a Corte como uma instituição que pode afetar suas metas e agendas políticas, fato que garantiria a politização dos processos de nomeação.

Para tais autores, a politização das Cortes é formulada como uma decorrência natural do processo político de nomeação, pois a partir do momento em que concebeu-se o fato das Cortes poderem emitir decisões com consequências políticas, os interessados nessas decisões passam a procurar influenciar e, se possível, controlar

\footnotetext{
II - dois terços pelo Congresso Nacional.

${ }^{30}$ PESSANHA, Charles. O congresso externo sob o controle das contas do tribunal de contas. Revista Insight Inteligência, no 21 , p.124. Disponível em: <http://www.insightinteligencia.com.br/21/>.

${ }^{31}$ GRIFFIN, Stephen M. Era Marbury: o judicial review em uma democracia de direitos. In: BIGONHA, Antonio Carlos Alpino e MOREIRA, Luiz (orgs.). Legitimidade da jurisdição constitucional. Rio de Janeiro: Lumen Juris, p. 251. 2010.

${ }^{32}$ No mesmo sentido pensa John Ferejohn: "Em certa medida, o aspecto político das nomeações para Cortes é tanto inevitável como legítimo em nossa estrutura governamental. (...) A regulação direta da atividade política é uma forma comum de judicialização, especialmente importante e crescente. Quando os eleitos veem que seus nomeados podem tornar-se seus reguladores, promotores e carcereiros, as apostas acerca da nomeação judicial alcançam um nível superior. (...) juízes e promotores têm proibido práticas políticas veneradas que estavam, indiscutivelmente, na fundação de partidos políticos, desde os primeiros anos de República." Ibid; p.43 e 61.
} 
nomeações para os tribunais e outras instituições legais. Conforme leciona John Ferejohn a "judicialização" da política tende a produzir a politização dos tribunais. Como resultado, o processo judicial de tomada de decisão tende a tornar-se politicamente exercido por outros meios." ${ }^{33}$

Ao analisar tais variáveis políticas, diversas sugestões são feitas, reformas, dentre as mais relevantes, o estabelecimento de uma "supermaioria" no Senado para as votações das nomeações, o que significaria que juízes recentemente nomeados precisariam ser aceitos por partidos e linhas ideológicas com maior adesão e homogeneidade, assim como limitar os juízes a exercerem um único mandato não renovável, de forma que não poderiam servir na Corte vitaliciamente. ${ }^{34}$

Não pretendemos, neste trabalho, adentrar no mérito das sugestões para o impasse da politização das Cortes criado por seu questionável processo de nomeação, ou pacificar se tal fenômeno é intrínseco e obrigatório devendo assumi-lo como premissa e corrigir suas eventuais imperfeições ou, pelo contrário, se deve ser refreado e entendido como um desvio no curso do processo de indicação pensado constitucionalmente.

Pretendemos sim trazer à tona que a politização das Cortes é um fenômeno real e concreto, e o processo de indicações políticas é uma de suas razões, o que robustece a análise da judicialização da política e controlabilidade de escolhas políticas consubstanciadas em políticas públicas, sob o enfoque das peculiaridades institucionais da Corte de Controle.

Nessa diapasão, Cortes se tornam lugares nos quais política substancial é feita, e juízes cada vez mais agem no sentido de regular a atividade política como um todo, seja a praticada pelos governantes diretamente enquanto representantes populares, ou por meio das entidades integrantes da Administração Indireta, como as Agências Reguladoras. Muito embora o controle de atos administrativos seja necessário e parte do regime democrático, pois o interesse da coletividade deve ser a finalidade maior do Estado, é preciso evitar o excesso de competência, o julgamento que ultrapassa as atribuições legais, sob pena de termos uma instituição disfuncional que não atende aos seus fins precípuos.

\section{AS POLITICAS PÚBLICAS ENQUANTO ESCOLHA ESTATAL E SUA FISCALIZAÇÃO POR CORTES DE CONTAS}

Não é de hoje o debate sobre a intervenção do Judiciário em face das políticas públicas, versus discricionariedade administrativa, opondo os que advogam pela autonomia dos gestores eleitos, em primazia ao

\footnotetext{
${ }^{33}$ Ibid; p.64

${ }^{34}$ Ibid; p.67
} 
princípio constitucional da separação de poderes ${ }^{35}$, e os que prezam pelo intervencionismo, seja ele intenso ou moderado, pautado pelos ditames da proporcionalidade e razoabilidade, avaliados casos a caso $^{36}$.

Este trabalho não pretende esgotar ou pacificar o tema, nem focar sua análise na atuação judiciária, trazida aqui em função da já comentada similitude dessa com a jurisdição de contas, com intuito de estabelecer entre ambas uma analogia. O que se pretende é inserir a discussão no âmbito do controle orçamentário à luz das peculiaridades da Corte de Contas da União apresentadas, jogando nova luz sobre esse debate do limite da controlabilidade das políticas públicas por Tribunais de Contas, ainda pouco explorado pela doutrina e jurisprudência.

Inicialmente, vale ressaltar que falar em discricionariedade difere de arbitrariedade ou autonomia na acepção privada da palavra, pois o gestor público ou governante está sujeito a limitações e controle sobre seus atos, inclusive os discricionários, pois deve agir em prol de um bem maior, para além de subjetividades. O próprio nome já diz, fala-se Administração Pública, exercício de funções públicas, o que veda a atuação em total liberalidade, pois o fim mediato dessa atuação é o interesse público indisponível, a coletividade.

Essa autonomia tem, portanto, limites definidos em lei, espaços nos quais a escolha por parte dos administradores é permitida, que responderão por tais atos no futuro. Se a lei delegou essa possibilidade de escolha de forma intencional, é claro que tal ato concretamente realizado não comporta ampla revisão por outra autoridade, se assim o fosse, não haveria sentido falar em discricionariedade. ${ }^{37}$ Segundo a doutrina clássica de Hely Lopes Meirelles, "a discricionariedade administrativa é a ferramenta jurídica que a ciência do Direito entrega ao administrador para que realize a gestão dos interesses sociais respondendo às necessidades de cada momento". ${ }^{38}$

A discricionariedade administrativa é fruto da multiplicidade e complexidade de atividades desempenhadas pelo Poder Público, pois o dia-a-dia da gestão pública é dinâmico, sempre com novos desafios e questionamentos, posto que atende vasta variedade de anseios e necessidades. Seria uma incumbência sem tamanho impor à Lei que, por mais minuciosa e bem elaborada que seja - o que muitas vezes não acontece, por

\footnotetext{
${ }^{35}$ Há jurisrpudência também nesse sentido: "Por outro lado, verifica-se do teor do Decreto Distrital no 31.6066/10, que fundamentou a edição da Portaria no 126610, que a revogação da "indicação" da área foi efetuada pela Administração por motivo de interesse público, matéria inserida no âmbito do mérito administrativo, o que impede a análise pelo Poder Judiciário, mormente em sede de mandado de segurança, sob pena de violação ao Princípio da Separação dos Poderes. A esse respeito, CRETELLA JR. assim leciona: "é o mérito um campo que fica totalmente na esfera discricionária da Administração Pública e nesta esfera o Poder Judiciário não tem a possibilidade de intervir." (BRASIL. Superior Tribunal de Justiça. AgRg no Recurso em MS n. 37.543 DF. Agravo Regimental no Recurso em Mandado de Segurança n. 20120065992-2.)

36 "Ademais disso, a separação de Poderes subordina ao controle jurisdicional. Os atos administrativos podem ser revistos pelo Judiciário, cabendo discutir adiante os limites da avaliação judicial sobre o chamado mérito do ato administrativo. No entanto, isso não autoriza que o Poder Judiciário assuma competências de natureza administrativa. Jurisprudência do STF "Desse modo, a decisão impugnada resvalou no subjetivismo, invadindo o âmbito da discricionariedade legislativa e administrativa, impondo providência diversa da legalmente determinada e adotada pela Administração, sem justificar, concretamente o porquê dessa medida (...)" (STA no 335. Rel Min. Gilmar Mendes. Julg. 12.6.2009. Dje, 23 jun. 2009) (JUSTEN, Marçal Filho. Curso de direito administrativo. 7. ed. p. 98. Belo Horizonte: Fórum, 2011).

${ }^{37}$ Ibid; p. 224.

${ }^{38}$ Direito Administrativo Brasileiro. 29. ed. p. 105/166.
} 
deficiências do nosso processo legislativo - abarcasse todas as possibilidade e situações futuras ou indicasse o melhor caminho para cada caso.

Diante desse cenário, tem se construído entendimento jurisprudencial no sentido de permitir-se o controle judicial de atos meritórios que apresentem defeitos, com base na violação à proporcionalidade, boa-fé, melhor gestão pública, razoabilidade, etc. ${ }^{39}$ Dessa forma, a limitação quanto ao objeto do controle pode dar-se em duas vertentes: uma ligada à legalidade, pois é preciso haver conformidade com a legislação, e outra à legitimidade do ato, que implica na conformidade com os princípios básicos da administração pública, sendo defeso ao Poder Judiciário, nessa última, pronunciar-se acerca da conveniência, oportunidade e/ou eficiência, isto é, sobre o mérito administrativo em si.

Ao transpor essa questão para o âmbito do controle orçamentário, vemos que o mesmo foi imbuído constitucionalmente de aferir a legalidade, legitimidade, economicidade dos gastos, o que não difere muito do que se fala em termos de Poder Judiciário. Contudo, como já dito, há diferenças substanciais na atuação de juízes e juízes de contas, os últimos dotados de margem de atuação mais ampla, não adstrita ao princípio da inércia ou ao que é trazido aos autos pelas partes, é um órgão de controle acima de tudo. A ausência de definições mais apuradas sobre o objeto de controle, em se tratando de políticas públicas, pode levar a inúmeros conflitos e excessos na relação controlado e controlador.

O Tribunal de Contas posiciona-se como revisor da gestão em todos seus aspectos (legalidade, materialidade, eficiência e eficácia) e sobre todos os atos, simples ou complexos, como as políticas estatais, amplitude essa que não contribui para o aperfeiçoamento da gestão, sendo muitas vezes excessivamente formalista e um mero entrave para a implementação daquelas. É o efeito do olhar duro, ${ }^{40}$ a desconfiança institucionalizada, a produzir a ossificação da atuação administrativa, distanciando-se do que deveria ser a melhor forma de controle externo.

Não se nega que a Corte de Contas, no intuito de atender aos ditames democráticos, tem o papel de aperfeiçoar a gestão pública, buscando a promoção da legalidade e eficiência nos atos administrativos, mas isso

39 "Em complemento a esse raciocínio, Maria Sylvia Zanella Di Pietro lembra a evolução das limitações impostas à discricionariedade administrativa e anota que, após a construção da teoria dos motivos determinantes, passou-se a admitir o controle judicial com base na violação de princípios gerais do direito, como a boa-fé e a proporcionalidade, afirmando que hoje, a discricionariedade administrativa é vista como uma liberdade de opção entre duas ou mais alternativas válidas perante o direito, e não apenas perante a lei, motivo pelo qual sofre maiores limitações, ficando muito mais complexa a atividade de controle (Discricionariedade técnica e discricionariedade administrativa, in Revista Brasileira de Direito Público, Belo Horizonte, ano 5, $\mathrm{n}^{\circ}$ 17, abr/jun 2007, pp. 77-78).” BRASIL. Superior Tribunal de Justiça. AgRg no Agravo em REsp n. 422.106 - RJ. Agravo Regimental no Agravo em Recurso Especial n 20130364004-7.

${ }^{40}$ SUNSTEIN, Cass; VERMEULE, Adrian. Interpretation and Institutions. Chicago Public Law \& Legal Theory Working Papers Series, n. 28, p.35. 2002: "Agora é bem documentado que tal revisão tem contribuído para a ossificação de "notice-and-comment rulemaking”, que agora leva anos, em parte como resultado do esforço para se afastar de desafios judiciais. Tendo em conta o risco de invalidação, muitas agências afastaram-se do "notice-and-comment rulemaking" por completo — como o NHTSA, por exemplo, atentando contra a promoção de segurança do automóvel, por exemplo, através de "ex post recalls", que é entendido como uma forma sem sentido de prosseguir." (tradução nossa) 
não significa que é um novo poder soberano no sistema de freios e contrapesos, fiscalizando a tudo e todos sem maiores ponderações.

À guisa de exemplo da postura que se fala, citamos caso em que, avaliando a opção estatal de usar arbitragem em dado contrato, o Tribunal afirma que "não se vincula nem ao juízo arbitral nem ao Poder Judiciário, devendo decidir de forma independente, conforme determina a Constituição Federal. Nessa linha, as lides decididas no âmbito do juízo arbitral poderão ser rediscutidas neste TCU”. ${ }^{41}$

Cabe pontuar, de forma breve, que uma sentença arbitral faz coisa julgada entre as partes, produzindo os mesmos efeitos da proferida pelos órgãos do Poder Judiciário e, se condenatória, constitui título executivo (Art. 31 da Lei de Arbitragem). ${ }^{42}$ Dito isso, não cabe falar em recurso da sentença arbitral para o Judiciário, ressalvada a possibilidade de pleitear a decretação de sua nulidade, dentro das hipóteses legais ${ }^{43}$.

Se a Lei estabeleceu que não cabe ao Judiciário ser instância revisora das decisões arbitrais, como poderia o TCU, em claro excesso de competência, posicionar-se como revisor das questões decididas no procedimento arbitral, sob as quais recai o manto da coisa julgada. ${ }^{44} \mathrm{~A}$ despeito de sua incorreção, tal decisão evidencia a desconsideração às possíveis consequências sistêmicas oriundas de se revisar algo já decidido, e produzindo efeitos entre o Estado e a outra parte.

Outro exemplo de intervenção, foi o caso do Edital referente ao Projeto do Trem de Alta Velocidade, que depois de muitas ressalvas, foi aprovado pelo TCU, no entanto, o Ministro José Jorge afirmou que, a seu ver, grandes investimentos em transportes urbanos seriam muito mais importantes, criticando o modelo de negócios elaborado pela Agência Nacional de Transporte Terrestre e pontuando que pela sua complexidade teria que olhar o projeto com "olho bem aberto" pois "poderia dar problema". 45

Há outro caso mais recente de análise de políticas públicas pela Corte de Contas, em que restou visível a relação conflituosa entre controlados e controlador, foi o do relatório sobre assistência social emitido em 2014. Tal documento gerou uma Nota de Repúdio por parte do Conselho Nacional de Assistência Social e uma

\footnotetext{
${ }^{41}$ Brasil. Tribunal de Contas da União. Acórdão 2094/2009 - Plenário - Processo no TC 006.588/2009-8, Entidade: Petróleo Brasileiro S.A. (Petrobras) Interessado: Congresso Nacional.

${ }^{42}$ Art. 31. A sentença arbitral produz, entre as partes e seus sucessores, os mesmos efeitos da sentença proferida pelos órgãos do Poder Judiciário e, sendo condenatória, constitui título executivo.

${ }^{43}$ Art. 33. A parte interessada poderá pleitear ao órgão do Poder Judiciário competente a decretação da nulidade da sentença arbitral, nos casos previstos nesta Lei. Art. 32. É nula a sentença arbitral se: I - for nulo o compromisso; II - emanou de quem não podia ser árbitro; III - não contiver os requisitos do art. 26 desta Lei; IV - for proferida fora dos limites da convenção de arbitragem; V - não decidir todo o litígio submetido à arbitragem; VI - comprovado que foi proferida por prevaricação, concussão ou corrupção passiva; VII - proferida fora do prazo, respeitado o disposto no art. 12, inciso III, desta Lei; e VIII - forem desrespeitados os princípios de que trata o art. $21, \$ 2^{\circ}$, desta Lei.

44“No caso da arbitragem, a decisão adotada na sentença arbitral é definitiva, podendo ser revisada apenas no tocante a aspectos muitos reduzidos, estabelecidos expressamente pela Lei 9.037/96. Porém, em nenhuma hipótese é viável a revisão da substância, do "mérito" da decisão adotada pelos árbitros." (CARDOSO, André Guskow. As Agências Reguladoras e a Arbitragem. In: PEREIRA, César Augusto G.; TALAMANI, Eduardo. Arbitragem e Poder Público. São Paulo: Saraiva, 2010.p.41.)

45 TCU vê riscos, mas dá aval a projeto para o TAV. Revista Ferroviária. 06.dez.2012 Disponível em: < http://www.revistaferroviaria.com.br/index.asp?InCdEditoria=2\&InCdMateria=17374>
} 
correspondente Nota de Desagravo, fato inédito, por parte do TCU, na qual afirmou ser "lamentável que o Governo Federal declare publicamente que os Ministros do TCU foram induzidos a equívoco em decorrência da 'ignorância dos técnicos' (Auditores), o que, se fosse verdade, poria em xeque as reais credenciais daqueles para a função de judicatura na esfera de controle externo." ${ }^{46}$

É certo que a questão opõe dois lados da mesma moeda, se por um lado não cabe negligenciar a importância do controle, até das questões referentes à legalidade formal, sob pena de facilitar irregularidades, de outro, formalidades que não evidenciem desvios de finalidade ou danos ao erário não podem obstaculizar a efetivação de políticas públicas, o que acaba por engessar o Estado e prejudicar a coletividade, pois poderia estar usufruindo de serviços em regime de maior qualidade e eficiência.

A suposta proteção à legalidade e interesse público primário não podem ser alegados em todo e qualquer caso, como se Cortes de Contas pudessem ser revisores supremos da atuação estatal, pois chegaríamos ao cenário em que governantes só gerem se autorizados e validados pelos entendimentos impostos aos controlados, a partir do que o Tribunal considera ser melhor e eficaz para atender aos anseios sociais. Os governantes eleitos são os responsáveis pela boa formulação de políticas públicas e posterior implementação, e não o TCU, sendo que ambos devem zelar pelo respeito aos princípios que pautam a atuação da Administração.

É preciso, antes de tudo, superar a desconfiança arcaica enraizada no funcionamento do controle externo brasileiro e o formalismo exacerbado, pois acabam impedindo que o controle contribua de fato para uma boa gestão dos gastos públicos, que é parte do intuito de um controle, que não pode ser um fim em si mesmo.

O diálogo entre instituições é um futuro a se almejar, no qual Executivo, Legislativo e TCU atuem em cooperação para alcançar o melhor funcionamento estatal no âmbito federal, contudo o caminho é longo, antes de tudo, as atribuições constitucionais e legais precisam ser respeitadas, rigorosamente, pela Corte de Contas.

Vale pontuar a importância e a força dessa instituição, reiterando que possui competências autônomas, a despeito de constar como auxiliar o Legislativo na função de controle externo, residindo na delimitação do alcance dessa autonomia a grande dificuldade prática. Por tudo exposto, é possível estabelecer que decisões de mérito dos entes fiscalizados escapam da competência da Corte, que deve ter como parâmetro a ocorrência ou não de ilegalidades e prejuízos ao erário e à coletividade.

É possível usarmos três noções para delimitar a atuação dessa instituição: objeto, conjunto de atos passíveis de fiscalização; parâmetro, referência adotada para análise do objeto e produto, conjunto de atos produzidos em decorrência dessa atividade. ${ }^{47}$ No último, há certa limitação legal, pois não pode sustar contratos,

\footnotetext{
${ }^{46}$ Nota Pública ANTC e CNSP. 11 de Setembro de 2014. Disponível em: <http://www.antcbrasil.org.br/index.php?secao=noticias\&visualizar_noticia=316>

${ }^{47}$ SUNDFELD, Ari Carlos; CÂMARA, Arruda Jacintho. Competências de Controle dos Tribunais de Contas - Possibilidades e Limites. Revista dos Tribunais, no 928, v. 102, Rio de Janeiro, p. 1115-1133.2003.
} 
por exemplo, estando adstrito a certo tipo de ordem, quando constatar ilegalidades em matéria financeira, orçamentária, contábil ou patrimonial. ${ }^{48}$

Evidencia-se, então, que não cabe a avaliação e revisão de toda e qualquer decisão administrativa, principalmente em se tratando de contratos, que possuem cada qual sua peculiaridade. Atentando sempre para a questão da grande extensão da influência dessa Corte em todos os atos que exara, incluindo o controle a "posteriori" das contas que recai sobre os gestores públicos, assim como a possibilidade de aplicação de multas a esses em caso de irregularidades.

\section{CONCLUSÃO}

Parte do fenômeno da judicialização da política transposto para o âmbito orçamentário, em uma de suas formas, significa avaliar a intervenção no processo de criação de políticas públicas, que até então eram feitas ou deveriam ser, pelo Poder Executivo e Legislativo e passam a ser partilhadas com os juízes de contas. Nesse contexto, a Instituição Superior de Controle torna-se instrumento de vigilância e correção dos atos governamentais; o que implica, muitas vezes, interferência nos processos políticos de criação da norma e definição de políticas públicas, bem como, do próprio comportamento dos atores políticos. ${ }^{49}$

O resultado disso é que os julgamentos de contas pelo Tribunal de Contas da União, que por suas próprias peculiaridades não poderia ser um Tribunal politicamente neutro, passam a efetivar a judicialização da política no âmbito do controle externo ao exercerem essa função fiscalizatória sobre os demais poderes. Segundo Tavares, ${ }^{50}$ não se deve enquadrar órgãos julgadores como neutros e livres de paixões, interesses e pressões em determinadas épocas, sendo perfeitamente possível que estes elementos sejam levados em consideração na feitura da decisão.

Tanto é assim que, motivado por tais questões, está em trâmite o Projeto de Emenda Constitucional no 329 de 2013 para promover mudanças no funcionamento das Cortes de Contas e seu respectivo Ministério Público. ${ }^{51}$ Menciona-se que existe um clamor social pela melhoria de serviços públicos relacionados à saúde, transporte, segurança pública, educação, temas que são sistematicamente analisados pelas Cortes de Contas, o

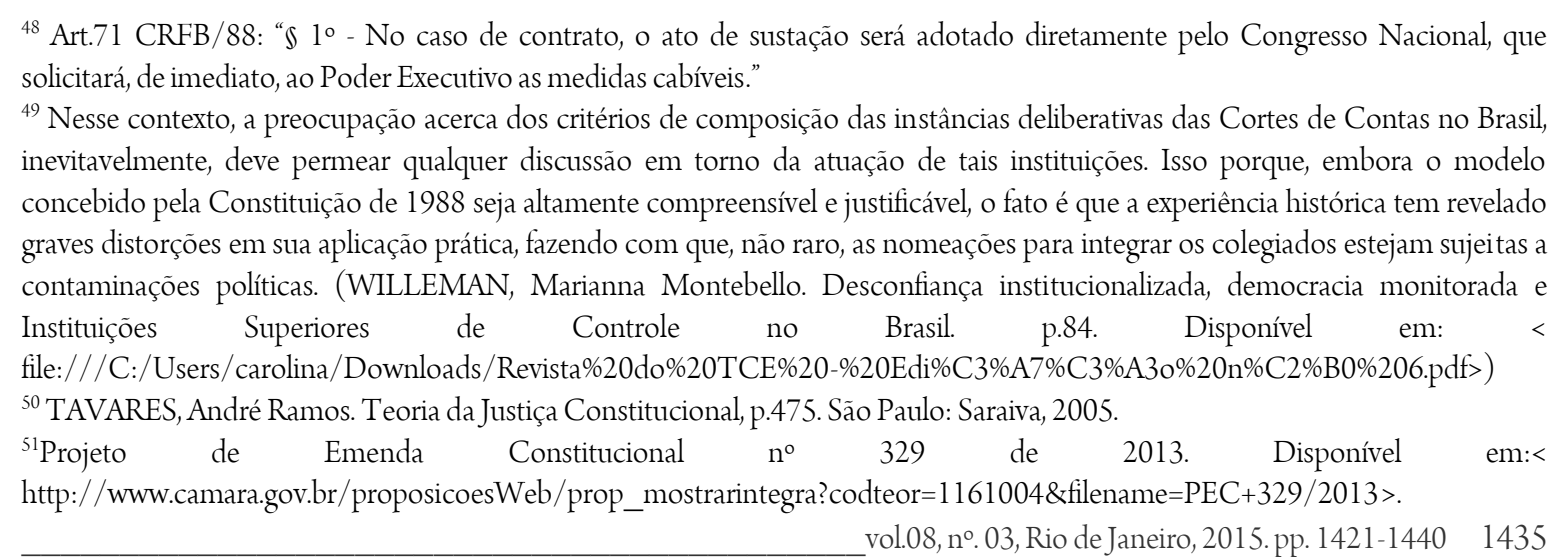


que gera a conclusão de que havendo problemas, existe também responsabilidade por parte do órgão fiscalizatório. Por vezes impõe-se uma barreira à efetivação de dada política pública benéfica à coletividade, enquanto outros setores continuam incipientes, sem maiores considerações, como menciona o projeto em questão.

Dentre as mudanças propostas, visando "afastar dessas Cortes a influência político-partidária", está a adoção de concurso público direto ou a solução intermediária, impondo o ingresso na carreira da magistratura de contas no cargo de Auditor Substituto de Conselheiro que passaria a ser chamado, por exemplo, de "Conselheiro Substituto". O modelo permite que se conjugue a necessidade de concurso com o mecanismo de promoção na carreira, usado no Judiciário, para se chegar aos Tribunais de Segunda Instância. A justificativa do Projeto ilustra bem tudo que foi exposto:

Recentemente, vem ganhando corpo dentro e fora dos Tribunais de Contas uma massa crítica de agentes públicos que vivem o dia a dia dessas instituições e, invariavelmente, concluem no sentido do esgotamento do modelo atual. (...) Rigorosamente, em tese, o modelo de controle externo vigente no Brasil, se fosse verdadeiramente implementado, seria plenamente adequado às finalidades de um controle moderno e ágil. (...) O problema é que a regra constitucional de conformação desses tribunais não é respeitada (...)

Aproximadamente $25 \%$ dos membros dos Tribunais de Contas estaduais não possuem a formação adequada para exercer a função. Mas o problema mais grave, porém, é o estreito vínculo mantido e cultivado entre muitos dos membros nomeados para essas Cortes e as forças políticas responsáveis pelas suas nomeações.

Estudo elaborado pelo Instituto Ethos, intitulado Sistema de Integridade nos Estados Brasileiros, identifica na falta de independência dos colegiados dos Tribunais de Contas elemento de comprometimento da boa governança nos Estados brasileiros. (grifos nossos)

A importância e o papel da Corte de Contas ora analisada, não são recentes, eminentes juristas como Pontes de Miranda e Rui Barbosa já ressaltavam sua posição sui generis. ${ }^{52}$ Nos dizeres do primeiro, ao abordar a Constituição de 1931, já se via a singularidade da Corte e seu posicionamento apartado em relação aos três poderes: "era órgão do Poder Judiciário, sui generis; órgão, também, sui generis, do Poder Legislativo. Criação posterior à teoria da separação dos poderes e fruto da prática, dessoava das linhas rígidas da tripartição".

Cabe consignar que gestores públicos não devem ser obstaculizados no cumprimento das políticas escolhidas por receio do olhar duro da Corte de fiscalização, pois tal posicionamento em nada acrescenta à boa

\footnotetext{
${ }^{52}$ FERNANDES, Jorge Ulisses Jacoby. Tribunais de Contas do Brasil: jurisdição e competência. Belo Horizonte: Ed.Fórum, 2003. p.133: "Pontes de Miranda, mantendo a coerência da doutrina que sufragava, situava o TCU no arcabouço constitucional, referindo-se à Constituição de 1931, nos seguintes termos: "era órgão do Poder Judiciário, sui generis; órgão, também, sui generis, do Poder Legislativo. Criação posterior à teoria da separação dos poderes e fruto da prática, dessoava das linhas rígidas da tripartição." Rui Barbosa também se manifesta no mesmo sentido: “Tribunal é, mas Tribunal sui generis. E explica: "corpo de magistratura intermediária à administração e à legislatura, que colocado em posição autônoma com atribuições de revisão e julgamento, cercado de garantias contra quaisquer ameaças, exerce funções vitais no organismo constitucional"
} vol.08, nº. 03, Rio de Janeiro, 2015.pp. 1421-1440 
gestão de recursos públicos. Se dada política pública, segundo agentes eleitos democraticamente, é opção que privilegia o interesse público encontrando-se dentro da legalidade, não deve ser retirada a possibilidade de fazê-la por uma instituição de controle que, usurpando competências de seus fiscalizados, exerce suas atribuições de forma incorreta e ultrapassada.

\title{
JUDICIALIZATION OF POLICY UNDER BUDGET CONTROL AND CONTROLLABILITY OF PUBLIC POLICIES
}

\begin{abstract}
There is an ongoing growing process of expansion of judicial power over policy and state spending, process started from the powers of the Federal Audit Court listed in the Brazilian Constitution of 1988, a process that is related to the new conception of State Democratic Rights that arose. This phenomenon can be called judicialization of policy under the budget control, and keep strong similarity with the familiar judicialization of politics carried out by judges, who imbued of activist posture begin to "create" rights, causing a real transfer of legislative power, witch was before exclusive of legislative and executive powers, and now is passed, in the case, to judges and courts of auditors. Such aggrandizement of duties in all courts, institutions whose duties are constitutionally defined, generates a series of new challenges. Through the analysis of argumentative strategies and institutional practices set out by the Brazilian Court of Account in decisions, in the light of their legal and constitutional competences, it is possible to discuss the limits of this process of "domesticalization" of policy and structural dilemmas resulting from the increase in its performance in the current Brazilian Constitutional State. It is necessary to evaluate the limits and extent of control exercised by this court over other state sectors, especially the Executive, great performer of discretionary public policies and also check in its emblematic decisions if consequentialist issues are
\end{abstract}


taken into consideration, since it is known that they have the potential to have significant impact on the behavior of other political actors.

Keywords: Judicialization of politics; discourse analysis; Court of Accounts; public policies; administrative discretion; separation of powers.

\section{REFERENCIAS}

ARAGÃO, Alexandre Santos de. As Parcerias Público-Privadas - PPP's no Direito Positivo Brasileiro. Revista Eletrônica de Direito Administrativo Econômico, Salvador, Instituto de Direito Público da Bahia, no .2, maio-junjul, 2005. Disponível em: http:/ /www.direitodoestado.com.br.Acesso em: 30. jun.2014

BRASIL. Constituição da República Federativa do Brasil de 1988. São Paulo: Revista dos Tribunais, 2011.

BRASIL. Lei n. 9.037 de 23 de setembro de 1996. Dispõe sobre a arbitragem Disponível em: < http: //www.planalto.gov.br>. Acesso em: 28.out.2014

BRASIL. Projeto de Emenda Constitucional no 329 de 2013. Altera a forma de composição dos Tribunais de Contas; submete os membros do Ministério Público de Contas ao Conselho Nacional do Ministério Público CNMP e os Conselheiros e Ministros dos Tribunais de Contas ao Conselho Nacional de Justiça - CNJ e dá outras providências. Disponível em: $<$ http://www.camara.gov.br/proposicoesWeb/prop_mostrarintegra?codteor $=1161004 \&$ filename=PEC $+329 / 2$ 013>. Acesso em: 26.jan.2015.

BRASIL. Superior Tribunal de Justiça. AgRg no Recurso em MS n. 37.543 DF. Agravo Regimental no Recurso em Mandado de Segurança n. 20120065992-2.

BRASIL. Superior Tribunal de Justiça. AgRg no Agravo em REsp n. 422.106 - RJ. Agravo Regimental no Agravo em Recurso Especial n 20130364004-7.

Brasil. Tribunal de Contas da União. Acórdão 2094/2009 - Plenário - Processo no TC 006.588/2009-8, Entidade: Petróleo Brasileiro S.A. (Petrobras) Interessado: Congresso Nacional.

BRITTO, Carlos Ayres. O Regime Constitucional dos Tribunais de Contas. Revista Diálogo Jurídico, Salvador, CAJ - Centro de Atualização Jurídica, v. I, no. 9, dezembro, 2001. Disponível em: $<$ http://www.direitopublico.com.br>. Acesso em: 19.jan.2015

CARDOSO, André Guskow. As Agências Reguladoras e a Arbitragem. In: PEREIRA, César Augusto G.; TALAMANI, Eduardo. Arbitragem e Poder Público. São Paulo: Saraiva, p.27, 2010.

CASTRO, Marcus Faro de. O Supremo Tribunal Federal e a Judicialização da Política. Revista Brasileira de Ciências Sociais, n. 34, vol. 12, p. 147-156, jun. 1997.

DA SILVA, José Afonso. Curso de direito constitucional positivo. 9. ed.rev. São Paulo: Malheiros, 1992. 
DE OLIVEIRA, Vanessa Elias. Judiciário e Privatizações no Brasil: Existe uma Judicialização da Política? Dados Revista de Ciências Sociais [On-line] vol. 48, núm. 3, julho-setembro, 2005, pp. 559-587, Universidade do Estado do Rio de Janeiro, Brasil. Disponível em:<http://www.redalyc.org/articulo.oa?id=21848304> Acesso em: 25.abr.2015.

FERNANDES, Jorge Ulisses Jacoby. Tribunais de Contas do Brasil: jurisdição e competência. Belo Horizonte: Ed. Fórum, p.133, 2003.

FEREJOHN, John. Judicializing Politics, Politicizing Law. p.42. Disponível em< http://www.law.duke.edu/journals/65LCPFerejohn.>. Acesso em: 13.fev.2015.

GRIFFIN, Stephen M. Era Marbury: o judicial review em uma democracia de direitos. In: BIGONHA, Antonio Carlos Alpino e MOREIRA, Luiz (orgs.). Legitimidade da jurisdição constitucional. Rio de Janeiro: Lumen Juris, p.251.2010.

JUSTEN, Marçal Filho. Curso de direito administrativo. 7. ed. Belo Horizonte: Fórum, 2011.

MEIRELLES, Hely Lopes. Direito Administrativo Brasileiro. 29. ed. São Paulo: Malheiros, 2004.

WILLEMAN, Marianna Montebello. Desconfiança institucionalizada, democracia monitorada e Instituições Superiores de Controle no Brasil. Disponível em: <http://bibliotecadigital.fgv.br/ojs/index.php/rda/article/viewFile/10649/9643> Acesso em: 21.jan.2015.

Nota Pública ANTC e CNSP. 11 de Setembro de 2014. Disponível em: <http://www.antcbrasil.org.br/index.php?secao=noticias\&visualizar_noticia=316>. Acesso em: 26.jan. 2015.

PARDINI, Frederico. Tribunais de contas: órgão de destaque constitucional. 1997. Tese (Doutoramento em direito público ) - Faculdade de Direito da Universidade Federal de Minas Gerais, Belo Horizonte.

PESSANHA, Charles. O congresso externo sob o controle das contas do tribunal de contas. Revista Insight Inteligência, no 21, p.124. Disponível em: <http://www.insightinteligencia.com.br/21/>. Acesso em: 30.jun.2014.

SUNSTEIN, Cass; VERMEULE, Adrian. Interpretation and Institutions. Chicago Public Law \& Legal Theory Working Papers Series, No. 28, p.35. 2002

SUNDFELD, Ari Carlos; CÂMARA, Arruda Jacintho. Competências de Controle dos Tribunais de Contas Possibilidades e Limites. Revista dos Tribunais, nº 928, v. 102, Rio de Janeiro, p. 1115-1133.2003.

SANTOS, Fabiano. O Poder Legislativo no Presidencialismo de Coalizão. Belo Horizonte: Ed, UFMG; Rio de Janeiro: IUPERJ, 2003.

TATE, Neal. Why the expansion of judicial power? In: TATE, Neal; VALLINDER, Torbjörn. The Global Expansion of judicial power. New York: New York University Press, 1995. p. 27-37.

TAVARES, André Ramos. Teoria da Justiça Constitucional. São Paulo: Saraiva, 2005.

WERNECK VIANNA, Luiz et al. A judicialização da política e das relações sociais no Brasil. Rio de Janeiro: Revan, 1999. 
REVISTA FERROVIÁRIA. TCU vê riscos, mas dá aval a projeto para o TAV. 06.dez.2012 Disponível em: < ttp://www.revistaferroviaria.com.br/index.asp?InCdEditoria=2\&InCdMateria=17374>, Acesso em: 26.jan.2015.

Trabalho enviado em 22 de fevereiro de 2015.

Aceito em 25 de maio de 2015. 